\title{
Epidemiological investigation of Pseudomonas aeruginosa nosocomial bacteraemia isolates by PCR-based DNA fingerprinting analysis
}

\author{
Y. LIU, A. DAVIN-REGLI, C. BOSI, R. N. CHARREL and C. BOLLET \\ Laboratoire d'Hygiène et de Microbiologie et Comité de Lutte contre I'Infection Nosocomiale, Hôpital Salvator, \\ 249 Bd Ste Marguerite, 13009 Marseille, France
}

\begin{abstract}
Between July 1994 and March 1995, 64 isolates of Pseudomonas aeruginosa were implicated in bacteraemia in 25 cancer patients in five wards of two hospitals. These, together with 24 environmental isolates and one isolate from a bacteraemia in a noncancer patient were examined by three PCR-based DNA fingerprinting methods: random amplified polymorphic DNA (RAPD), enterobacterial-repetitive intergenic consensus (ERIC)-PCR, and 16S-23S spacer region-based RAPD. These methods were reproducible, discriminatory and showed close agreement; all indicated that 47 isolates that had caused bacteraemia in 19 cancer patients were indistinguishable. Seventeen other isolates that had caused bacteraemia in 10 cancer patients were discriminated into eight further groups, and the $\mathbf{2 4}$ environmental and non-cancer patient isolates into further distinct groups. No environmental source of the epidemic strain was found, but it was suspected that the outbreak was related to infusion implants.
\end{abstract}

\section{Introduction}

Pseudomonas aeruginosa is an opportunist pathogen frequently isolated in the hospital from moist environmental sources and equipment [1]. Septicaemic infections are an important cause of mortality in immunocompromised patients [2], particularly in neutropenic cancer patients [1]. Investigations of the nosocomial epidemiology of $P$. aeruginosa have been hampered by the inadequate discriminatory capacity of classical phenotypic methods such as serotyping, phage typing, pyocin typing and biotyping. Modern DNAbased techniques, including restriction fragment length polymorphism (RFLP) demonstrated by hybridisation with species-specific coding regions such as the exotoxin A gene, the pilin gene and a broad-spectrum probe of Escherichia coli rDNA [3-7], macrorestriction analysis by pulsed-field gel electrophoresis (PFGE) $[5$, 8-10] or field inversion gel electrophoresis (FIGE) [11, 12] and restriction endonuclease analysis (REA) [13] have been applied in epidemiological studies of $P$.

Received 14 Sept., 1995; revised version accepted 11 March 1996.

Corresponding author: Dr C. Bollet. aeruginosa. However, these techniques are expensive, slow, and some require specific gene probes.

Of the PCR-based techniques, random amplified polymorphic DNA (RAPD) [14] is based on the amplification of DNA segments with a single primer of arbitrary nucleotide sequence, and has been widely used for the epidemiological investigation of many micro-organisms [15] including $P$. aeruginosa $[10,16$, 17]. The 126-bp enterobacterial repetitive intergenic consensus (ERIC) elements contain a highly conserved central inverted repeat located in extragenic regions; this has been used as a primer in PCR (ERIC-PCR) to obtain DNA fingerprints for several bacterial species $[18,19]$. The spacer regions separating the genes coding for $16 \mathrm{~S}, 23 \mathrm{~S}$ and $5 \mathrm{~S}$ rRNA are characterised by a high degree of sequence variation at the genus and species level [20]. The diversity is mainly due to variations in the number and type of tRNA sequences found within the spacer. PCR amplification of spacer regions between the $16 \mathrm{~S}$ and $23 \mathrm{~S}$ RNA genes has been used for characterisation of a broad range of bacteria [20]. Spacer region PCR products of Mycobacterium tuberculosis strains have been used as target DNA for RAPD amplification that gave discriminatory results [21]. 
In this study, RAPD, ERIC-PCR and 16S-23S spacer region polymorphism-based RAPD analysis were compared in the investigation of a possible outbreak of $P$. aeruginosa bacteraemia in cancer patients in two hospitals in Marseille.

\section{Materials and methods}

\section{Isolates and patients}

A total of $89 P$. aeruginosa strains was selected for investigation. Sixty-four isolates from 25 cancer patients were implicated in bacteraemic episodes between July 1994 and March 1995. These patients had various malignancies, including breast cancer, cerebral tumour, lymphoma, hepatocellular carcinoma and uterine cancer, and all developed bacteraemia during chemotherapy administered via an infusion implant. They were in five wards (oncology, radiotherapy, gynaecology, dermatology and neurosurgery) at two hospitals. A further 24 strains from the hospital environment (water, siphon and surfaces) in these five wards, and one isolate implicated in bacteraemia in a non-cancer patient with no infusion implant, who was hospitalised for surgery in another ward, were collected during the same period.

\section{Identification, susceptibility testing and $O$ serotyping}

All isolates were identified as $P$. aeruginosa according to colony morphology, Gram's stain appearance, oxidase reaction, growth at $41{ }^{\circ} \mathrm{C}$, and reaction patterns in the API $20 \mathrm{NE}$ system (bioMérieux, Marcy l'Etoile, France) and API 100 carbon auxanogram strips (bioMérieux). Antibiotic susceptibility testing was performed with the Walkaway 40 System (SanofiDiagnostics Pasteur, Marnes-la-Coquette, France). O serotypes were determined by the International Antigenic Typing System (Diagnostic Pasteur) [22]. Reactions with commercial $\mathrm{O}$ antisera were controlled with reference strains.

\section{DNA extraction}

Isolates were grown in trypticase-soya broth at $37^{\circ} \mathrm{C}$ for $24 \mathrm{~h}$ and DNA was extracted by the Chelex technique as described by De Lamballerie et al. [23].

\section{$R A P D$ and ERIC-PCR conditions}

Amplification reactions were performed in a total volume of $47 \mu \mathrm{l}$ containing $100 \mu \mathrm{M}$ each of dATP, dCTP, dGTP and dTTP, $0.2 \mu \mathrm{M}$ of primer AP12H (5'CGGCCCCTGT-3') or ERIC-2 (5'-AAGTAAGTGACTGGGGTGAGCG-3'), 25 ng of template DNA and 1.25 units of Taq polymerase (Perkin-Elmer/Cetus, Norwalk, CT, USA) in PCR buffer (20 mM Tris-HCl, $\mathrm{pH} \quad 8.3 ; 50 \mathrm{mM} \mathrm{KCl}, 2.5 \mathrm{mM} \mathrm{MgCl}_{2}$ ). A negative control without template DNA was.included in each experiment. The reaction mixtures were overlaid with mineral oil and subjected to amplification in a DNA thermal cycler (TR 2, Cera-Labo, Aubervilliers, France) programmed for 45 cycles of $1 \mathrm{~min}$ at $94^{\circ} \mathrm{C}$, $1 \mathrm{~min}$ at $45^{\circ} \mathrm{C}$ and $1 \mathrm{~min}$ at $74^{\circ} \mathrm{C}$. After the last cycle, samples were maintained at $74^{\circ} \mathrm{C}$ for $10 \mathrm{~min}$. Amplification products were compared by electrophoresis of $10-\mu 1$ samples on agarose $1.2 \%$ gels (Eurogentec, Angers, France) in Tris-acetate buffer $(0.04 \mathrm{M}$ Trisacetate, $0.001 \mathrm{M}$ EDTA, pH 8.2), stained with ethidium bromide and photographed on a UV light transilluminator. The presence or absence of bands in a gel lane was determined by visual inspection of the patterns independently by two observers. Fingerprint patterns were interpreted without knowledge of epidemiological data. Fingerprint patterns were considered similar (indistinguishable) if all bands had the same migration distance or if there were no more than two band differences for patterns comprising 6-11 products or three band differences for patterns comprising 12-18 products. These criteria for classifying isolates as indistinguishable or different were established in previous studies [24, 25]. Variation in intensity and shape of bands were not considered to be differences. In addition, photographs of the gels were scanned and analysed with a Bio Image wholeband system, Scanner 3+ (Millipore). Mol.wt standards were included (Marker V, Boehringer, Boehringer Mannheim, Germany). The mol.wts of sample bands were calculated automatically from reference bands allowing evaluation of mol. wts to c. $1 \%$.

\section{PCR amplification of $16 S-23 S$ spacer region and $R A P D$ based upon this region}

PCR was performed as follows: a $50-\mu 1$ volume of reaction mixture containing $25 \mathrm{ng}$ of isolate DNA, $50 \mathrm{mM} \mathrm{KCl}, 10 \mathrm{mM}$ Tris- $\mathrm{HCl}(\mathrm{pH} 8.8), 1.5 \mathrm{mM} \mathrm{MgCl}_{2}$, Triton X-100 $0.1 \%, 100 \mu \mathrm{M}$ of each deoxynucleotide triphosphate (Boehringer Mannheim), $62.5 \mathrm{ng}$ of each of two oligonucleotide primers G1 (5'-GAAGTCGTAACAAGG- $3^{\prime}$ ) and L1 (5'-CAAGGCATCCACCGT$3^{\prime}$ ) previously selected [20] and 1.3 units of Taq DNA polymerase (Perkin-Elmer/Cetus) was subjected to 25 amplification cycles of denaturation at $94^{\circ} \mathrm{C}$ for $1 \mathrm{~min}$, annealing at $55^{\circ} \mathrm{C}$ for $7 \mathrm{~min}$ and extension at $72^{\circ} \mathrm{C}$ for $2 \mathrm{~min}$. After the last cycle, samples were maintained at $72^{\circ} \mathrm{C}$ for $7 \mathrm{~min}$. The PCR products $(10 \mu \mathrm{l})$ were separated by electrophoresis on agarose $1.2 \%$ gel (Eurogentec, Angers) in Tris-acetate buffer $(0.04 \mathrm{M}$ Tris-acetate, $0.001 \mathrm{M}$ EDTA, $\mathrm{pH}$ 8.2). The gels were stained with ethidium bromide and photographed on an UV light transilluminator. A mol.wt standard was included (Marker V, Boehringer). The remaining PCR product was precipitated with ethanol and resuspended in TE buffer (10 mM Tris- $\mathrm{HCl}, \mathrm{pH} 8.0,1 \mathrm{mM}$ EDTA) for use as target DNA for RAPD; $15 \mathrm{ng}$ of this, and $0.25 \mu \mathrm{M}$ of primer AP12H or AP4 (5'-TCA CGA TGC $\left.A-3^{\prime}\right)$, were amplified under the conditions described above for RAPD. 


\section{Reproducibility of DNA fingerprints}

Fingerprint profiles generated from independent DNA preparations extracted from single-colony cultures at different times and amplified separately were run side by side on an agarose gel to determine the reproducibility of the three PCR-based DNA fingerprinting methods.

\section{Results}

\section{Identification}

All isolates grew at $41^{\circ} \mathrm{C}$. Colonies from the 47 clinical isolates were rough and dwarf after growth for $24 \mathrm{~h}$ on blood agar. They were identified as $P$. aeruginosa with the API $20 \mathrm{NE}$ system and all clinical isolates yielded the same pattern (0154575). All isolates showed the pattern characteristic of $P$. aeruginosa in API 100 carbon auxanogram strips

\section{Antibiograms}

All clinical isolates were susceptible to azlocillin, piperacillin, ticarcillin, cefsulodin, ceftazidime, aztreonam, imipenem, gentamicin, tobramycin, amikacin and ciprofloxacin. They were of intermediate susceptibility to moxalactam, cefoperazone and aztreonam, and resistant to chloramphenicol and trimethoprim-sulphamethoxazole.

\section{Serotyping}

All clinical strains were non-agglutinable. Of the 24 environmental isolates, eight were of serotype O6, two of serotype $\mathrm{Ol}$, one of serotype $\mathrm{O} 10$ and one of serotype $\mathrm{O} 12$; three were non-agglutinable and nine were polyagglutinable.

\section{PCR analyses}

In RAPD with the AP12H primer, nine distinct patterns were found. RAPD pattern 1 comprised 48 cancer patient isolates; patterns $2-5$ comprised the remaining 16 isolates from cancer patients. The non-cancer patient isolate belonged to RAPD pattern 6 , and the 24 environmental isolates yielded patterns 7,8 and 9 (Fig. 1; Table 1).

ERIC-PCR yielded 12 typing patterns. Pattern 1 comprised 51 cancer patient isolates; patterns 2-8 comprised the remaining 13 cancer patient isolates. The non-cancer patient isolate gave pattern 9 and the 24 environmental isolates yielded three further patterns (Fig. 2; Table 1).

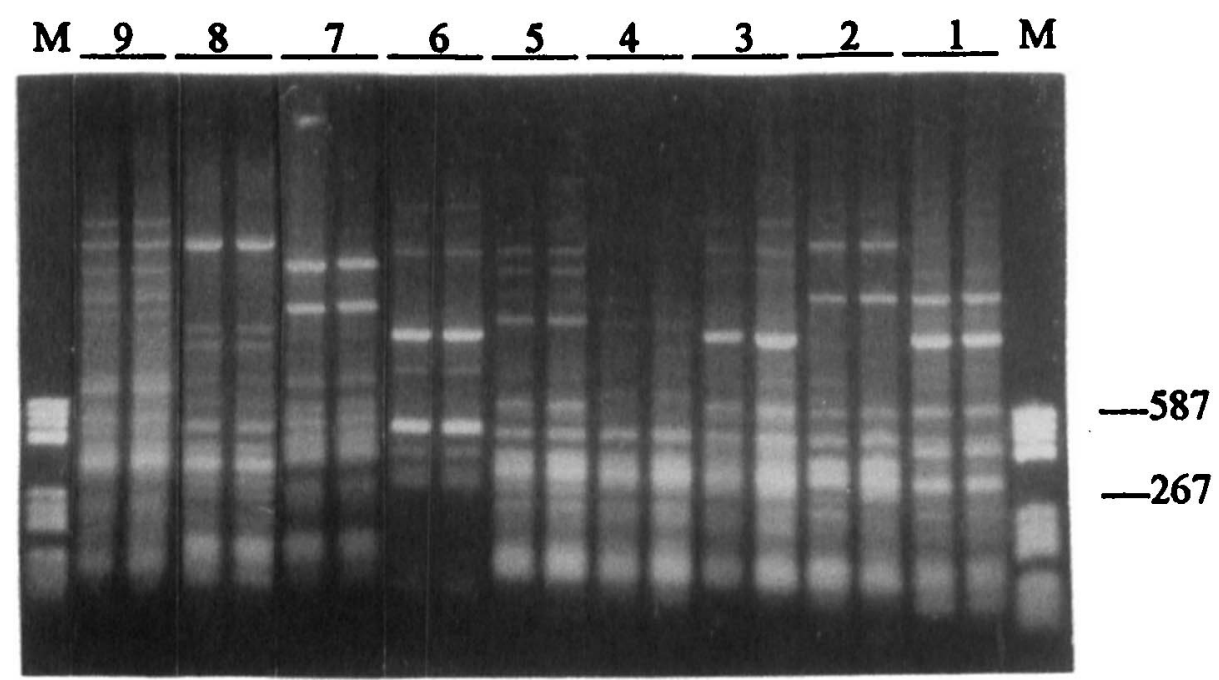

Fig. 1. Representative paired replicate lanes of the nine RAPD types obtained with primer AP12H. Each strain was selected to represent a specific type. Types 1-5 were clinical isolates; type 6 was a clinical control strain; types 7-9 were environmental isolates. Lane $\mathrm{M}$, mol.wt marker (bp).

Table 1. Typing results of three PCR-based DNA fingerprinting methods for 64 $P$. aeruginosa clinical isolates from five wards

\begin{tabular}{lccccc}
\hline $\begin{array}{l}\text { Number of } \\
\text { patients }\end{array}$ & $\begin{array}{c}\text { Number of } \\
\text { isolates }\end{array}$ & $\begin{array}{c}\text { RAPD } \\
\text { pattern }\end{array}$ & $\begin{array}{c}\text { ERIC-PCR } \\
\text { pattern }\end{array}$ & $\begin{array}{c}\text { 16S-23S spacer } \\
\text { RAPD pattern }\end{array}$ & $\begin{array}{c}\text { Combined } \\
\text { group }\end{array}$ \\
\hline 19 & 47 & 1 & 1 & 1 & I \\
3 & 6 & 2 & $1,5,7$ & 3 & II \\
2 & 2 & 2 & 2,6 & 2 & III \\
1 & 3 & 5 & 3 & 3 & IV \\
1 & 1 & 4 & 4 & 5 & V \\
1 & 2 & 4 & 5 & 6 & VI \\
1 & 1 & 1 & 8 & 3 & VII \\
1 & 1 & 3 & 1 & 3 & VIII \\
1 & 1 & 5 & 1 & 4 & IX \\
\hline
\end{tabular}




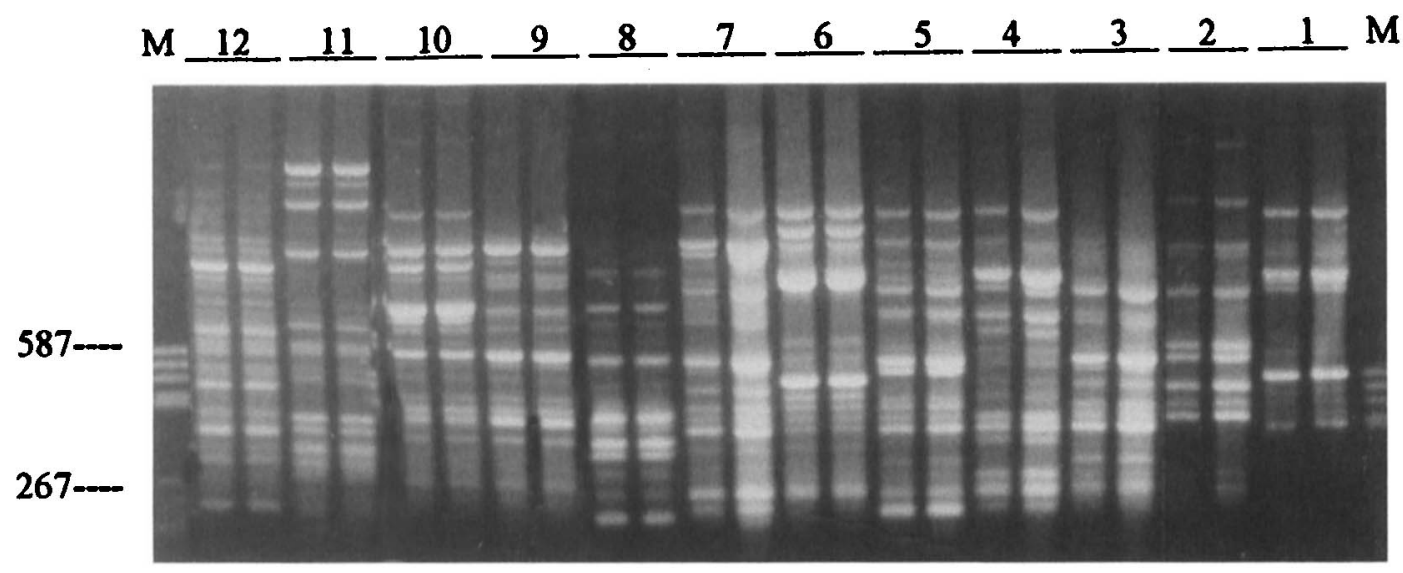

Fig. 2. Representative paired replicate lanes of the 12 ERIC types obtained with primer ERIC 2. Each strain was selected to represent a specific type. Types 1-8 were clinical isolates; type 9 was a clinical control strain; types 10-12 were environmental isolates Lane $\mathrm{M}$, mol.wt marker (bp)

All isolates shared three common fragments of 356 , 570 and $1033 \mathrm{bp}$ in the $16 \mathrm{~S}-23 \mathrm{~S}$ spacer region amplification products and were indistinguishable (data not shown).

However, when RAPD with AP4 primer was performed with the amplified spacer products as the target, nine patterns were resolved. Pattern 1 comprised 47 cancer patient isolates; patterns 2-6 comprised the remaining 17 cancer patient isolates. The non-cancer patient isolate gave pattern 7 and the 24 environmental isolates were distributed among typing patterns 8 and 9 (Fig. 3; Table 1).

The profiles obtained with AP4 primer RAPD of the spacer-region products were less complex and easier to interpret than those obtained with RAPD of whole-cell DNA, or ERIC-PCR. However, RAPD of the spacer product with primer AP12H yielded a single uniform pattern, so the choice of the primer seems to be critical.

\section{Reproducibility of DNA fingerprints}

The reproducibility of fingerprint profiles from different DNA preparation of the same strain was investi- gated by analysis of DNA from separate cultures extracted at different times. In each case, identical profiles were generated, although differences in band intensity were present.

\section{Combined interpretation of the results of the three fingerprint methods}

The results showed good agreement. In combination, the three methods allowed classification of the isolates into 13 groups. Group I comprised 47 isolates from 19 cancer patients in five wards of the two hospitals. Groups II-IX comprised the remaining 17 cancer patient isolates. Fig. 4 shows the distribution of the 64 clinical isolates in the five wards. The non-cancer patient isolate belonged to group X (Table 1). The 24 environmental isolates were distributed among three other groups (data not shown), and were considered to be clearly different from the clinical strains.

\section{Epidemiological investigation}

During 8 months, an epidemic type of $P$. aeruginosa was responsible for bacteraemia in 19 cancer patients during their chemotherapy. The results of this study

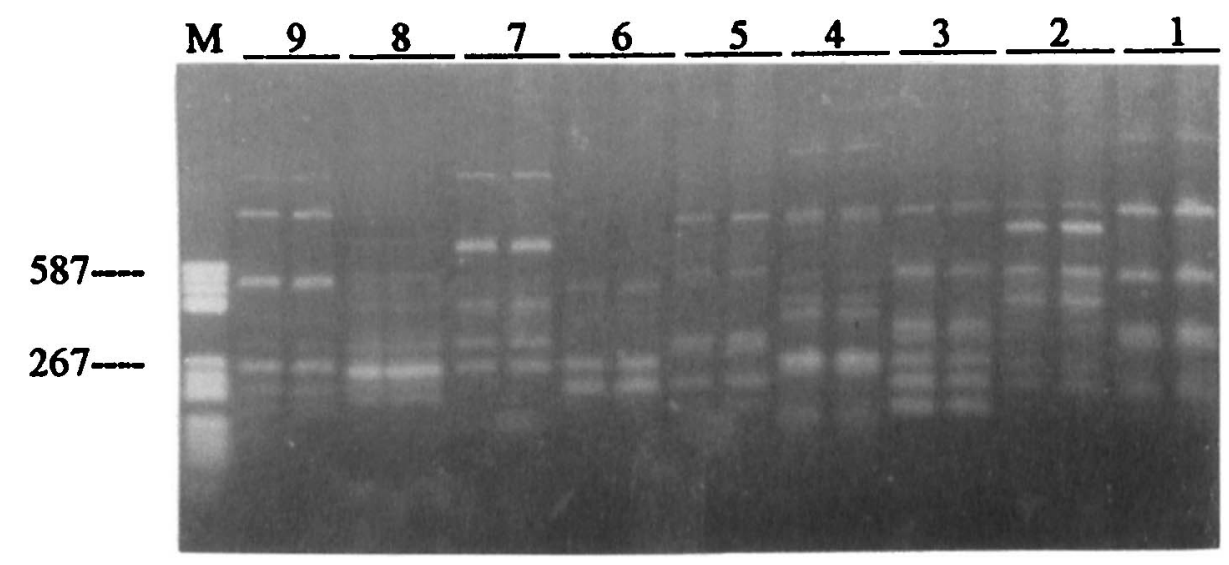

Fig. 3. Representative paired replicate lanes of the nine RAPD profiles with primer AP4 of the $16 \mathrm{~S}-23 \mathrm{~S}$ spacer region products of $P$, aeruginosa isolates. Types 1-6 were clinical isolates; type 7 was a clinical control strain; types 8 and 9 were environmental isolates. Lane $\mathrm{M}$, mol.wt marker (bp). 


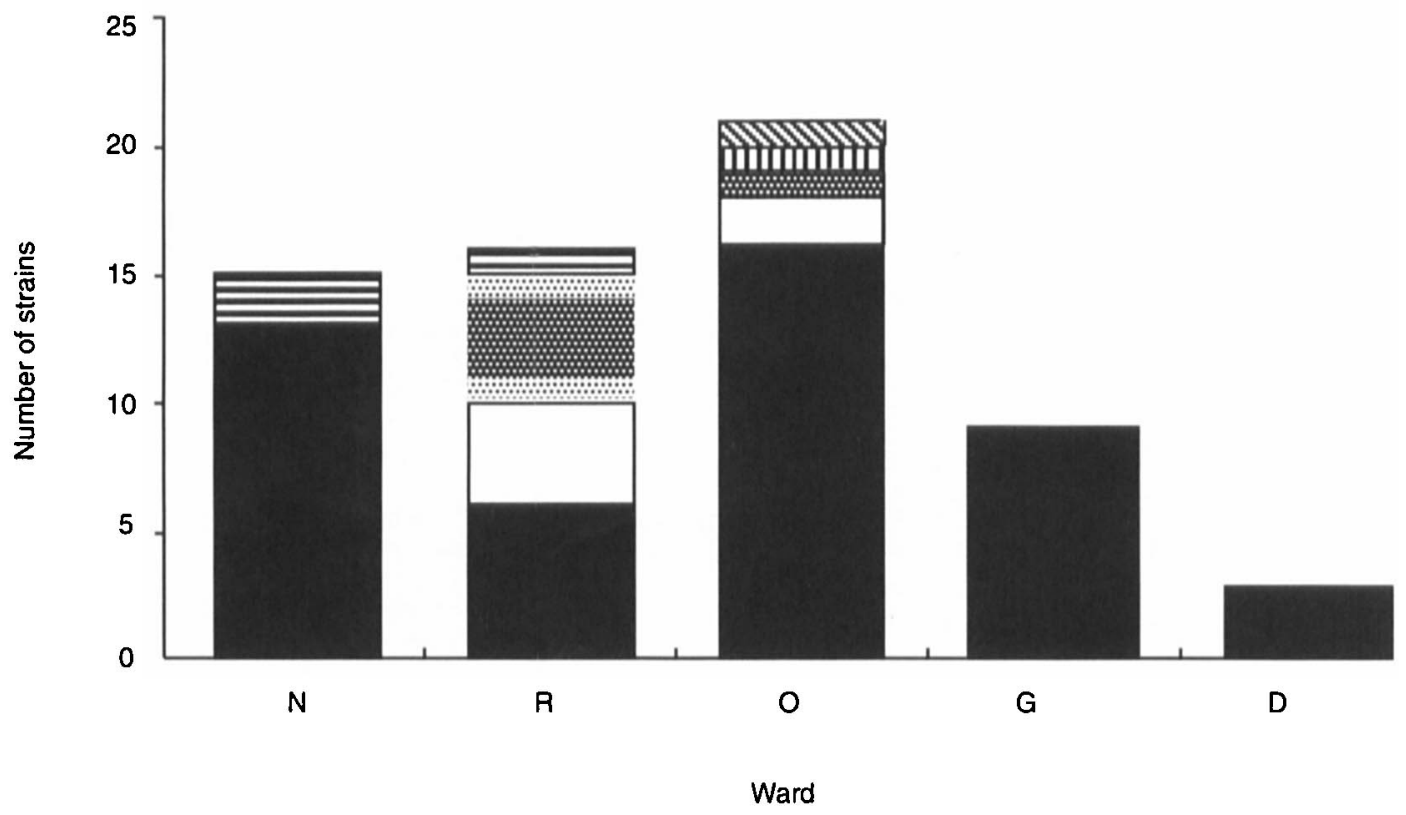

Fig. 4. Diagrammatic representation of bacteraemic $P$. aeruginosa isolates from 25 cancer patients between July 1994 and March 1995 in five wards. Each symbol corresponds to a specific combined group: $\mathbf{0}, \mathrm{I} ;$; , VI(N) or VII(R); $\square, \mathrm{II}$; , III; 园, IV; , V; , VIII; . IX. N, neurosurgery ward; R, radiotherapy; O, oncology; G, gynaecology; D, dermatology.

indicated that the $P$. aeruginosa bacteraemia cases might be related to the presence of infusion implants. These were implanted by two surgeons who shared the same materials and antiseptic solutions in the same unit. Contamination from the hands of one or both surgeons, the shared equipment or an environmental source could have explained the outbreak. However, no positive fingertip impression cultures from the surgeons, environment samples or equipment samples were obtained. As bacteraemia cases were observed 2 weeks-6 months after surgical implantation of the devices, contamination could have occurred during manipulation of infusion implants for the administration of anticancer therapy. However, bacteriological culture of some infusion implants removed from infected patients did not yield $P$. aeruginosa. Similarly, $P$. aeruginosa was not isolated from anticancer therapy infusates. No other case of $P$. aeruginosa bacteraemia was observed in these patients and the outbreak stopped after hospital personnel were informed about the risk of bacterial contamination during implantation and manipulation of infusion implants.

\section{Discussion}

Investigations of outbreaks of nosocomial infection due to $P$. aeruginosa are hampered by the inadequate discriminatory capacity of phenotypic markers, but with the advent of DNA-based techniques, stable and discriminatory epidemiological markers have become available. Typing systems used for epidemiological investigation should have a high degree of typability and reproducibility and be sensitive enough to distinguish between isolates that are similar but not identical. First DNA-based approaches used DNA fragment patterns after restriction endonuclease cleavage [13]. Difficulties in interpretation of the complex banding patterns led to the use of specific gene probes or rare-cutting restriction endonucleases to generate patterns with few fragments. Chromosomal fingerprinting with DNA probes or macrorestriction analysis by pulsed-field gel electrophoresis (PFGE) have been employed for epidemiological typing of $P$. aeruginosa [4-12]. However, Grundmann et al. were the first to compare the discriminatory power and the reproducibility of hybridisation of restricted chromosomal DNA with a specific (tox A) probe, ribotyping and PFGE [5]. They concluded that PFGE was the most powerful tool for studying the epidemiology of $P$. aeruginosa because of its high discriminatory capacity, good reproducibility and ease of interpretation. Moreover, Martin et al. [7] used ribotyping for molecular typing of strains of $P$. aeruginosa from patients with cystic fibrosis and observed a low degree of heterogeneity of rRNA operons. They considered that ribotyping would not be a valuable method for epidemiological studies with $P$. aeruginosa.

At the same time, the labour-intensive nature of macrorestriction typing prompted Kersulyte et al. to compare PFGE with a PCR-based typing method, arbitrarily primed-PCR (AP-PCR), which was easier to perform [10]. They found an excellent correlation between PFGE and AP-PCR. For a similar result with equivalent discrimination, AP-PCR presented advantages of rapidity and simplicity and was recommended by the authors for initial screening with many strains of $P$. aeruginosa are to be typed.

In the present study, three PCR-based DNA fingerprinting methods were compared for investigating the 
epidemiological relationship between $P$. aeruginosa isolates that had caused bacteraemia in cancer patients. This paper reports the first application of ERICPCR and $16 \mathrm{~S}-23 \mathrm{~S}$ spacer region-based RAPD to the epidemiological typing of $P$. aeruginosa and the first comparison between three PCR typing methods. RAPD and ERIC-PCR methods generated reproducible fingerprint profiles from extracted DNA of isolates cultured at different time. However, experimental parameters such as DNA isolation methods, buffer composition, primer or DNA template concentration affect the production of reproducible fingerprints. Investigations of the reproducibility of random PCR typing methods have enabled us to standardise those parameters routinely in our laboratory [26, 27].

Combination of the results of the three methods suggested that most of the $P$. aeruginosa isolates causing bacteraemia in cancer patients were indistinguishable and represented an epidemic clone. It also showed that the 24 isolates from the environment of the cancer patients were dissimilar from the isolates causing bacteraemia. Consequently, no environmental reservoir of the outbreak strain was found, although it was suspected that the outbreak was related to infusion implants.

RAPD and ERIC-PCR are generally used together in our laboratory and they always gave results in close agreement. The results of this study have shown that the analysis of polymorphism of the $16 \mathrm{~S}-23 \mathrm{~S}$ RNA spacer region by RAPD is a useful alternative, despite the requirement of a double procedure. Despite problems of reproducibility, which can be circumvented with experience, RAPD and ERIC-PCR are very useful in the epidemiological investigation of nosocomial outbreaks of $P$. aeruginosa infection for most clinical laboratories.

In conclusion, the three PCR-based typing methods showed similar discrimination for $P^{4}$ aeruginosa isolates. PCR-based typing methods were simple to do and to interpret and had the advantages of typability and discriminatory capacity equivalent to macrorestriction analysis.

\section{References}

1. Rolston KV, Bodey GP. Pseudomonas aeruginosa infection in cancer patients. Cancer Invest 1992; 10: 43-59.

2. Miller PJ, Wenzel RP. Etiologic organisms as independent predictors of death and morbidity associated with bloodstream infections. J Infect Dis 1987; 156: 471-477.

3. Richard P, Le Floch R, Chamoux C, Pannier M, Espaze E Richet H. Pseudomonas aeruginosa outbreak in a burn unit: role of antimicrobials in the emergence of multiply resistant strains. J Infect Dis 1994; 170: 377-383.

4. Fegan M, Francis P, Hayward AC, Fuerst JA. Heterogeneity, persistence, and distribution of Pseudomonas aeruginosa genotypes in cystic fibrosis patients. J Clin Microbiol 1991; 29: 2151-2157.

5. Grundmann H, Schneider C, Hartung D, Daschner FD, Pitt TL Discriminatory power of three DNA-based typing techniques for Pseudomonas aeruginosa. J Clin Microbiol 1995; 33: 528 534.

6. Speert DP, Campbell ME, Farmer SW, Volpel K, Joffe AM, Paranchych W. Use of a pilin gene probe to study molecular epidemiology of Pseudomonas aeruginosa. J Clin Microbiol 1989; 27: 2589-2593.

7. Martin C, Ait Ichou M, Massicot P, Goudeau A, Quentin R. Genetic diversity of Pseudomonas aeruginosa strains isolated from patients with cystic fibrosis revealed by Restriction Fragment Length Polymorphism of the rRNA gene region $J$ Clin Microbiol 1995; 33: 1461-1466.

8. Poh CL, Yeo CC, Tay L. Genome fingerprinting by pulsed-field gel electrophoresis and ribotyping to differentiate Pseudomonas aeruginosa serotype 011 strains. Eur J Clin Microbiol Infect Dis 1992; 11: 817-822.

9. Struelens MJ, Schwam V, Deplano A, Baran D. Genome macrorestriction analysis of diversity and variability of Pseudomonas aeruginosa strains infecting cystic fibrosis patients. J Clin Microbiol 1993; 31: 2320-2326.

10. Kersulyte D, Struelens MJ, Deplano A, Berg DE. Comparison of Arbitrarily Primed PCR and Macrorestriction (Pulsed-Field Gel Electrophoresis) typing of Pseudomonas aeruginosa strains from cystic fibrosis patients. J Clin Microbiol 1995; 33: 2216 2219.

11. Grothues D, Koopmann U, von der Hardt $H$, Tümmler B Genome fingerprinting of Pseudomonas aeruginosa indicates colonization of cystic fibrosis siblings with closely related strains. J Clin Microbiol 1988; 26: 1973-1977.

12. Boukadida J, de Montalembert M, Gaillard JL et al. Outbreak of gut colonization by Pseudomonas aeruginosa in immunocompromised children undergoing total digestive decontamination: analysis by pulsed-field electrophoresis. J Clin Microbiol 1991; 29: 2068-2071.

13. Maher WE, Kobe M, Fass RJ. Restriction endonuclease analysis of clinical Pseudomonas aeruginosa strains: useful epidemiologic data from a simple and rapid method. $J$ Clin Microbiol 1993; 31: 1426-1429.

14. Williams JGK, Kubelik AR, Livak KJ, Rafalski JA, Tingey SV DNA polymorphisms amplified by arbitrary primers are usefu as genetic markers. Nucleic Acids Res 1990; 18: 6531-6535.

15. van Belkum A. DNA fingerprinting of medically important microorganisms by use of PCR. Clin Microbiol Rev 1994; 7 174-184.

16. Elaichouni A, Verschraegen G, Claeys G, Devleeschouwer M Godard C, Vanneechoutte M. Pseudomonas aeruginosa serotype O12 outbreak studied by arbitrary primer PCR. J Clin Microbiol 1994; 32: 666-671.

17. Kerr JR, Moore JE, Curran MD et al. Investigation of a nosocomial outbreak of Pseudomonas aeruginosa pneumonia in an intensive care unit by random amplification of polymorphic DNA assay. $J$ Hosp Infect 1995; 30: 125-131.

18. Versalovic J, Koeuth T, Lupski JR. Distribution of repetitive DNA sequences in eubacteria and application to fingerprinting of bacterial genomes. Nucleic Acids Res 1991; 19: 6823-6831.

19. Louws FJ, Fulbright DW, Stephens CT, de Bruijn FJ. Specific genomic fingerprints of phytopathogenic Xanthomonas and Pseudomonas pathovars and strains generated with repetitive sequences and PCR. Appl Environ Microbiol 1994; 60: 22862295.

20. Jensen MA, Webster JA, Straus N. Rapid identification of bacteria on the basis of polymerase chain reaction-amplified ribosomal DNA spacer polymorphisms. Appl Environ Microbiol 1993; 59: 945-952.

21. Abed Y, Davin-Regli A, Bollet C, de Micco P. Efficient discrimination of Mycobacterium tuberculosis strains by $16 \mathrm{~S}-$ $23 \mathrm{~S}$ spacer region-based random amplified polymorphic DNA analysis. J Clin Microbiol 1995; 33: 1418-1420.

22. Pitt TL. A comparison of flagellar typing and phage typing as means of subdividing the $\mathrm{O}$ groups of Pseudomonas aeruginosa. J Med Microbiol 1981; 14: 261-270.

23. De Lamballerie X, Zandotti C, Vignoli C, Bollet C, De Micco P. A one-step microbial DNA extraction method using 'Chelex 100' suitable for gene amplification. Res Microbiol 1992; 143: 785-790

24. Reboli AC, Houston ED, Monteforte JS, Wood CA, Hamill RJ. Discrimination of epidemic and sporadic isolates of Acinetobacter baumannii by repetitive element PCR-mediated DNA fingerprinting. $J$ Clin Microbiol 1994; 32: 2635-2640.

25. Woods CR, Versalovic J, Koeuth T, Lupski JR. Analysis of 
relationships among isolates of Citrobacter diversus by using DNA fingerprints generated by repetitive sequence-based primers in the polymerase chain reaction. J Clin Microbiol 1992; 30: 2921-2929

26. Abed Y, Davin A, Charrel RN, Bollet C, De Micco P. Variation of RAPD-fingerprint patterns using different DNA- extraction methods with Gram-positive bacteria. World $J$ Microbiol Biotechnol 1995; 11: 238-239.

27. Davin-Regli A, Abed Y, Charrel RN, Bollet C, De Micco P. Variations in DNA concentrations significantly affect the reproducibility of RAPD fingerprint patterns. Res Microbiol 1995; 146: 561-568. 